\title{
Relationship between Diet, Physical Activity and the Development of Uterine Fibroids
}

\author{
Nemat Ismail Abdel Aziz Ismail, Lecturer \\ Obstetric and Gynecologic Nursing, Faculty of Nursing, Damanhour University \\ Sabah Lotfy Mohamed, Lecturer \\ Obstetric and Gynecologic Nursing, Faculty of Nursing, Zagazig University
}

\begin{abstract}
Uterine fibroids are noncancerous growths that develop in muscular wall of uterus. It is claimed that consuming certain types of food in excess in addition to assuming a sedentary life style are risk factors for the development of uterine fibroids. Objective: Explore the relationship between diet, physical activity and the development of uterine fibroids. Setting: The study was carried out in the out-patient gynecologic clinic affiliated to Zagazig University Hospital. Subjects: It comprised a purposive sample of 300 women, divided into two equal groups (150 each). The study group included women diagnosed with uterine fibroids and the control group included women free from uterine fibroids. Tools: Three tools were used to collect the necessary data; a structured interview schedule, short-form Food Frequency Questionnaire (FFQ) and International Physical Activity Questionnaire (IPAQ). Results: The study revealed that higher consumption of meat and fats is significantly associated with an increase risk of uterine fibroids development. While the higher intake of vegetables, grains and fruits are significantly associated with decrease in development of uterine fibroids. High physical activity is associated with lower prevalence of uterine fibroids. Conclusion: The higher intake of vegetables, grains and fruits as well as high physical activity is associated with lower prevalence of uterine fibroids, and a high intake of meat and fats is associated with a higher prevalence of uterine fibroids. Recommendations: Educational program to nurses working in maternity and gynecological settings about the importance of teaching women about prevention of uterine fibroids through consuming a healthy diet and regular performance of physical activity.
\end{abstract}

Kevwords: Uterine fibroids, Diet, Physical activity, Risk factors.

\section{Introduction}

Uterine fibroids, (also known as myomas or leiomyomas) are very common noncancerous growths that develop in muscular wall of uterus. It is benign, monoclonal tumor of the smooth muscle cells of the myometrium. Its incidence is about $30 \%$ to $70 \%$ according to different diagnostic methods. They are often described according to their location within the uterus. Subserous fibroids are located in the outer wall of the uterus. These often appear localized on the outside surface of the uterus or may be attached to the outside surface by a pedicle. Submucous fibroids are located inside the uterine cavity beneath the lining of the uterus. Intramural fibroids are located within the muscular wall of the uterus $^{(1-4)}$.

The vast majority of fibroids are asymptomatic but symptomatic fibroids can cause significant morbidity in women and affect their quality of life. The symptomatic fibroids are generally associated with numerous clinical problems including menstrual bleeding disorders, anemia and pelvic pain. In addition, they may cause reproductive disorders such as infertility and abortion. In addition to adverse 
pregnancy outcomes such as preterm labor, fetal malpresentation, increased need for caesarean section, and postpartum hemorrhage ${ }^{(5,6)}$. Although uterine fibroids are rarely associated with mortality, yet they can cause significantly increased health care costs and negative health experiences. The treatment of women with uterine fibroids must be individualized, based on symptoms, size and rate of growth of the fibroids and woman's desire for fertility ${ }^{(7)}$.

Both reproductive and environmental factors are believed to influence the risk of fibroids. Relevant literature suggests that increased parity is associated with a decreased risk, possibly through elimination of incipient fibroids as the uterus involutes post partum $^{(8)}$. In addition, the use of progestin-only injectable contraceptives is associated with a reduced risk. On the other hand, early menarche, the use of oral contraceptives before 16 years of age, history of infertility, young age at first birth, current alcohol consumption and cigarette smoking are associated with an increased risk $^{(9)}$. Some studies have shown that a high body-mass index is a risk factor. Specific genetic mutations have also been linked to fibroid formation ${ }^{(10)}$.

Sex steroids, estrogen and progesterone, are believed to play a role in fibroids enlargement. This is based on the fact that uterine fibroids tend to grow during the reproductive years and regress postmenopausally. The concentration of estrogen and estrogen receptors in fibroids is about ten times larger than in the normal myometrium. It is believed that sex steroids promote the development of fibroids by stimulating inappropriate expression of growth factors ${ }^{(11)}$. Estrogen and progesterone act as physiologic regulators of gene expression by activating nuclear receptors which are themselves transcription factors. In this way estrogen and progesterone play a key role in regulating genes that direct cell growth ${ }^{(12)}$.

Nowadays, it is believed that $70 \%$ of illnesses are related to individual's life style.
W.H.O reported in 2002 that certain changes in dietary habits, reduced physical activity and tobacco consumption has been related to the occurrence of some chronic diseases in developing countries. Lifestyle influences such as diet, exposure to stress and exercise can either support or hinder the body. In general it is widely recognized that a healthy balanced diet and regular exercise can maintain a healthy well functioning body ${ }^{(13)}$. Hormones are also believed to be directly influenced by these lifestyle choices. They are influencing factors in reproductive health both directly and indirectly. Consequently, lifestyle factors can be modified to enhance overall wellbeing. They play a key role in determining reproductive health and can positively or negatively influence it $^{(14)}$.

A woman's hormone balance plays a part in the development of most cancerous and noncancerous tumors. Diet has been associated with estrogen levels. Protection against breast and endometrial cancers by vegetable and fruit intake may be mediated by isoflavonoids, which have moderate estrogenic activity and may therefore compete with other endogenous estrogens $^{(15)}$. A high-fat diet can increase the risk of several cancers, including endometrial cancer. Because fatty foods are also high-calorie foods, a high-fat diet can lead to obesity, which is a well-known endometrial cancer risk factor. Some scientists think that fatty foods may also have a direct effect on estrogen metabolism, which increases endometrial cancer risk ${ }^{(16)}$.

Physical activity is hypothesized to decrease endometrial cancer risk because it reduces serum levels of oestradiol and increases levels of sex hormone binding globulin, the binding protein for oestradiol. These effects of physical activity may be mediated through prevention of weight gain. More generally, effects on oestrogen metabolism may at least in part operate directly, or through decreasing body fat stores. On the other hand, spending excessive amount of time sitting is 
associated with increased risk of insulin resistance, which increases the risk of endometrial cancer. Sedentary life may also be linked to endometrial cancer risk through insulin-related mechanisms via low levels of energy expenditure, as well as via weight gain, which are both associated with sitting time ${ }^{(17,18)}$.

Little is known about the actual association between diet and physical activity on the risk of uterine fibroids in Egypt. This study aimed to shed some light on this association. This would help the nurse/midwife to provide a specifically tailored health education regarding prevention of uterine fibroids.

\section{Aim of the Study}

This study aimed to explore the relationship between diet, physical activity and the development of uterine fibroids.

\section{Research Questions:}

1. What is the relationship between women's diet and the development of uterine fibroids?

2. What is the relationship between women's physical activity and the development of uterine fibroids?

\section{Materials and Method}

Materials

Design: A case-control design was used for this study.

Setting: The study was carried out in the out-patient gynecologic clinic affiliated to Zagazig University Hospital. This setting was selected because it has an increased turn-over of women with different socioeconomic back ground. In addition, it receives patients from all over the governorate.

Subjects: The study comprised 300 women either diagnosed with uterine fibroids or free from this condition and fulfilling the following criteria: Age between 20-50 years, with no malignant disease, not pregnant or not breastfeeding, no acute internal or infectious disease and willing to participate in the study.

Epi -Info program was used to estimate the sample size using the following parameters.

1. Target population 1292 per 3 months.

2. Expected frequency $=50 \%$

3. Acceptable error $=5 \%$

4. Confidence coefficient $=95 \%$

5. Sample size $=300$

6. Power analysis $=80 \%$

The study subjects were selected by the non-probability sampling technique (purposive sampling). During data collection, women attending the previously mentioned setting and fulfilling the inclusion criteria were selected. The study subjects were divided equally into two groups:

Study group included 150 women diagnosed with uterine fibroids; the diagnosis of fibroids was confirmed by ultrasound.

Control group involved 150 women free from uterine fibroids. Women who attended this clinic for another reason except uterine fibroids; the diagnosis of fibroids were excluded by ultrasound.

Study and control groups were selected at the same time according to the subjects availability at data collection time.

Tools: Three tools were used in this study:

Tool I: Socio-demographic and Clinical Data Structured Interview Schedule

It was developed by the researchers to collect the following data:

a. Socio-demographic data such as age, level of education, occupation, residence and family income.

b. Menstrual history such as age at menarche, rhythm, interval, duration and amount of menstrual flow. 
c. Reproductive history such as gravidity, parity and number of abortion.

d. Age at marriage

e. Smoking status either active or passive.

f. Anthropometric measurements such as height and weight to calculate body mass index (B M I).

Tool II: Short-form Food Frequency Questionnaire (FFO)

It was developed by Block et al. $(1990)^{(19)}$ to assess dietary habits. The short form of the FFQ questionnaire was modified by the researchers to suit the Egyptian culture such as omitting pork and wine from the sheet. Then it was translated into Arabic by specialist in English language translation. The version was revised and then back translated into English by another translator. The translation was refined after back translation until agreement was obtained among the two translators. The short-form FFQ consisted of a total of 10 items: 1) meat, 2) fish \& egg, 3) cereals, breads \& starches, 4) vegetables \& grains, 5) dairy food, 6) fruits, 7) sweets foods, 8) beverages, 9) fats, and 10) salty food. For each food, the participant was asked to fill in how often, on average, she had consumed the food during the previous week then it was applied over the year, and her usual portion size. For each item, the answer was classified into four frequency categories:1) never/less than one day per week, 2) one or two days per week, 3) three to five days per week and 4) everyday or more. The total frequency of food intake was classified as follows: low (never/less than one day per week), intermediate (one or two days per week), and high (three or more days per week) ${ }^{(19)}$.
Tool III: International Physical Activity Questionnaire (IPAQ)

It was developed by IPAQ Research Committee (1998) ${ }^{(20)}$, IPAQ Research Committee translated this Questionnaire from English to 12 languages including Arabic language to facilitate its use worldwide. The International Physical Activity Questionnaire (IPAQ) was designed for population surveillance of physical activity among adults aged 15-69 years. It was designed in two forms (long and short), the long form contains 27 items while the short form contains 7 items. The official Arabic short version of the IPAQ was used in this study. It includes 7 items providing information on time spent walking, in vigorous- and moderate intensity physical activities and their frequency (days per week) and duration (minutes per day) during the previous 7 days. A measure that describes the total volume of physical activity was calculated by weighting each type of activity by its energy requirements defined in metabolic equivalents (METs). One MET equals the resting metabolic rate of approximately 1 $\mathrm{kcal} / \mathrm{kg} / \mathrm{h}$. Using the Ainsworth et al. compendium of the average MET score for each type of activity, the following values were used for the analysis of IPAQ data: walking at work $=3.3$ METs, moderate yard work $=4.0$ METs and vigorous intensity in leisure $=8.0$ METs. Total scores were expressed as MET-minutes per week (MET level $\times$ minutes of activity/day $\times$ days per week $)^{(21)}$. The subjects are classified according to their total scores into three categories: Low active (achieved total physical activity less than 600 METminutes/weeks), Moderate active (achieved total physical activity from $\mathbf{6 0 0}$ to less than 1500 MET-minutes/weeks) and High active (achieved total physical activity of $\mathbf{1 5 0 0}$ or more MET-minutes/week) ${ }^{(20)}$. 


\section{Method}

- Official permission to carry out the study was obtained from the responsible authorities.

- Tool I was developed by the researchers after reviewing relevant literature then checked for content validity by a jury of 5 experts in the field.

- Tool II was adapted and necessary modifications were done then translated into Arabic language. It was tested for content validity by a jury of 5 experts in the field. It was tested for reliability by test- retest technique the Cronbach's alpha test was 0.85 .

- Tool III was adopted from IPAQ Research Committee (1998) ${ }^{(20)}$, and tested for validity and reliability by El-Gilany et al. $(2011)^{(22)}$, the testretest correlation coefficients was 0.87 .

- A pilot study was carried out on 30 women. Based on the findings of the pilot study, tools were reviewed, some questions were clarified.

- Women attending gynecologic clinics were interviewed before and after performance of gynecological examination. Those diagnosed with uterine fibroid were assigned to the study group and women free from uterine fibroid were assigned to the control group.

- Each woman either in the study or control group was interviewed individually by the researchers after explaining the purpose of the study, and then the necessary data were collected. The time taken to complete the study tools ranged from 20 to 25 minutes for each woman.

- Collection of data covered a period of 12 months starting from beginning of January 2015 till the end of December, 2015. Two days per week were specified for data collection (Sunday and Tuesday). The subjects in control group were collected during 4 months, while the subjects in the study group were collected during 12 months, reason for this diversity was the small number of women diagnosed with uterine fibroid than control one.

\section{Ethical considerations:}

Informed oral consent was obtained from all women after providing an appropriate explanation about the purpose of the study. Those who agreed to participate were assured about confidentiality, privacy and their right to withdraw from the study at any time.

\section{Statistical Analysis}

Data entry and statistical analysis was done after collection of data by using Statistical Package for Social Sciences (SPSS) version 16. Descriptive and analytical statistics were used such as percentages, means and standard deviations, Chi-square-test, Fisher Exact-test, and Ttest. Significance was adopted at $\mathrm{p}<0.05$ for interpretation of results of tests of significance, all p-values are two-sided.

\section{Results}

Table (1) indicates the distribution of study subjects according to their sociodemographic characteristics, age at marriage, smoking status and Body mass index. As regards age, $42.7 \%$ and $36 \%$ of the study and control groups respectively were 30 to less than 40 years old. Secondary education was evident among nearly the same percent of the study and control groups (50\%and 46\% respectively); $60 \%$ and $62 \%$ of the study and control groups respectively were housewives, and $48 \%$ and $54 \%$ of them were from rural areas. $46 \%$ and $44 \%$ of the study and control groups 
respectively reported having enough family income. Age at marriage was less than 20 years among two-fifths (40\%) of the study group compared to $46 \%$ of the control one. All the study and control groups $(100 \%)$ were non-smokers. While $56 \%$ of the study group were passive smokers (exposed to smoking by family member), compared to $48 \%$ of the control one. Mean Body mass index was $26.447 \pm 1.789$ and $26.620 \pm 1.566$ among the study and control groups respectively. No significant difference was found between the two groups in relation to their socio-demographic characteristics, age at marriage, smoking status and Body mass index.

Table (2) shows the distribution of the study subjects according to their menstrual history. The mean age at menarche was $13.973 \pm 1.266$ and $13.747 \pm 1.057$ among the study and control groups respectively. The amount of menstrual flow was moderate among $52 \%$ and $46.7 \%$ of the study and control groups respectively. Meanwhile, the rhythm was regular among the majority of the study and the control groups $(73.3 \%$ \& $80 \%)$ respectively. The mean duration of menstruation was $5.973 \pm 0.794$ days \& $6.033 \pm 0.746$ days among both groups respectively. On the other hand, the mean interval of menstruation was $27.327 \pm 0.871$ days \& 27.207 \pm 1.064 days among women in the two groups respectively. No significant difference was found between the two groups in relation to their mean age at menarche, amount of menstrual flow, rhythm of menstruation, mean duration of menstruation and mean interval of menstruation $(\mathrm{P}=0.093, \mathrm{P}=0.639, \mathrm{P}=0.173$, $\mathrm{P}=0.500 \& \mathrm{P}=0.286$ respectively).

Table (3) reflects the distribution of the study subjects according to their reproductive history. No significant difference was observed between the two groups in this respect. Where more than one-half (58\% and $54.7 \%)$ of the study and control groups respectively had three or more pregnancies. Concerning parity, more than one half (52\% and $54.7 \%)$ of the study and the control groups respectively had one or two deliveries. About three fifth $(60 \%$ \& $63.3 \%$ ) of them had no abortion.

Table (4) exhibits the distribution of the study subjects according to their consumption of food. It was observed that more than one-half $(54.7 \%)$ of the study group consume high meat (e.g., red meat, chicken....) compared to only $16 \%$ of the control one. Only $30 \%$ of the study group eat high vegetables \& grains compared to $58.7 \%$ of the control group. It is interesting to notice that only $10 \%$ of the study group eat high fruits compared to three-fifths (60\%) of the control group. Three-fifths $(60 \%)$ of the study group consume high fats (e.g., butter, margarine....) in their diet compared to less than one-half $(49.3 \%)$ of the control one. Highly statistically significant differences were found between both groups regarding meat, vegetables \& grains, fruits and fats intake $(\mathrm{P}=0.000)$.

On the other hand, nearly the same percent of the study and control groups $(53.3 \%$ and $50 \%$ respectively) had intermediate fish and egg intake. $65.3 \%$ of the study group reported high dairy foods intake compared to $73.3 \%$ of the control one. Nearly the same percent of the study and control groups $44 \%$ \& $42.7 \%$ respectively reported high sweet foods (e.g., jam, halawa.....) intake. The majority of the study and control groups $93.3 \%$ \& $97.3 \%$ respectively had high cereals, breads \& starches intake. $62.7 \% \& 60 \%$ of the study and control groups respectively claimed high beverages intake. High salty foods intake were observed among $(40 \%$ \& $45.3 \%$ ) of the study and control groups respectively. No statistically significant differences were found between both groups regarding fish \& egg, dairy foods, sweets foods, cereals, breads \& starches, beverages and salty foods intake $(\mathrm{P}=0.581, \mathrm{P}=0.323$, $\mathrm{P}=0.218, \quad \mathrm{P}=0.260, \mathrm{P}=0.097 \quad \& \quad \mathrm{P}=0.175$ respectively).

Table (5) shows the number and percent distribution of the study subjects according to their level of physical activity. It was 
observed that more than one-half $(56 \%)$ of the study group were low active during the last 7 days compared to only $20 \%$ of the control one. The difference between the two groups -in this respect- was highly statistically significant $(\mathrm{P}=0.000)$.

\section{Discussion}

Eating a healthy and varied diet may be a key component of maintaining good overall health. However, there are certain vitamins and food groups that could have a greater impact on reproductive health than others. Dietary factors are of interest because of their antioxidant effects and their ability to modify endogenous hormones. Exercise helps maintain a healthy body composition, supports bone density, muscle development, cardiovascular health and enhances mood. It also supports the circulatory system including the lymphatic system which is involved in the removal of toxins from the body. Moderate exercise helps relieve stress on the body and mind and so has a remedial effect on the endocrine system helping to balance hormones. The pathogenesis of uterine fibroids is not well understood, but lifestyle factors including diet, physical activity have a potential effect on fibroids' growth and development ${ }^{(23,24)}$. The aim of this study was to explore the relationship between diet, physical activity and the development of uterine fibroids.

Although many studies ${ }^{(25-27)}$ found that the age, age at marriage, smoking status, body mass index, age at menarche, gravidity and parity are a risk factors for uterine fibroids development, the present study revealed no statistically significant difference between the study and control groups in relation to age, age at marriage, smoking status (either active or passive), body mass index, age at menarche, gravidity and parity (table 1, $2 \& 3$ ). This difference between the present study and the previous studies may help understand and/or justify the relevance of the forthcoming results of the current study. It may also provide a logic rational in relation to possible association of diet and physical activity with the development of uterine fibroids.

The present study revealed that high meat intake is associated with development of uterine fibroids, where significantly higher meat intake was observed by the study group than control group (Table 4). This finding may be attributed to the fact that fibroids are believed to be a hormonerelated disease ${ }^{(28)}$. Therefore, consuming foods that have an impact on hormone levels are thought to pose a risk. A diet high in meat, especially red meat, is naturally higher in saturated fat than a diet limiting these foods. Diets higher in saturated fat have been linked to higher estrogen levels, which could worsen the existing fibroids ${ }^{(29)}$. This result is similar to the results of Flick $G$ et al. $(2003)^{(30)}$ they did a review on etiology and pathogenesis of uterine myoma and found that the consumption of meat, pork and other meat products had increased the occurrence of uterine myoma. While, Chiaffarino et al. (1999) $)^{(31)}$ found a moderate association between the risk of uterine myomas and the consumption of beef, other red meat, and ham. They suggest that women who eat more than one serving per day of red meat have a $70 \%$ greater risk for uterine myoma, compared to women who eat the least. Similar results are found by Parazzini et al. $(2004)^{(32)}$. On the other hand, the same result contradicts $\mathrm{He}$ et al. $(2013)^{(33)}$ in China who reported no association between uterine fibroids and lifestyles including diet, physical activity and stress. They found that meat intake was not significantly associated with uterine fibroids development. This difference in the obtained results from the different studies may be related to the difference between the tools used to assess meat intake. Where in the latter, it included only the frequency of intake without an accurate estimation of each portion size.

The present study clarified that higher intake of vegetables \& grains are associated with a decreased risk of uterine fibroids. 
Where the intake of vegetables \& grains where statistically significantly higher among the control group than the study one (table 4). This may be due to the fact that vegetables and grains are good sources of dietary fibers, vitamins, minerals, antioxidants and phytochemicals. Dietary fiber can influence sex hormone and bile acid metabolism mainly though partially interrupting enterohepatic circulation, altering intestinal metabolism and increasing the fecal excretion of these compounds $^{(34)}$. Whole grains are also a good source of B vitamins - a class of nutrients the liver needs to convert estrogen to its weaker form, estriol. Once converted, estriol has little effect on the uterus, which may help reduce the risk of fibroid development ${ }^{(35)}$. This finding is in accordance with the findings of $\mathrm{He}$ et al. $(2013)^{(33)}$ who reported that vegetables and fruits intake were significantly inversely associated with fibroid risk. While Bani et al. $(2013)^{(36)}$ who studied the leiomyoma and nutrition elaborated that the mean score of vegetables intake in healthy women was significantly more than women with myoma $(p<0.05)$. Also, Chiaffarino et al. $(1999)^{(31)}$ investigated the Diet and Uterine Myomas and found that a high intake of green vegetables seems to have a protective effect against uterine fibroids. The present study result is also supported by Sahin et al. $(2007)^{(37)}$ who had studied the dietary tomato powder supplementation in the prevention of leiomyoma of the oviduct in the Japanese quail. Their results showed that using more antioxidant compounds such as tomato prevents uterine myoma.

The result of the present study showed that, higher intake of fruits is associated with decreased fibroids risk, where the intake of fruits was statistically higher among control group than study one (table 4). This may be attributed to the fact that uterine fibroids are sex hormone dependent tumors and complex interactions of estrogen, progesterone and growth factors have been proposed. Estrogen has been considered as the major promoter of fibroid growth but recent biochemical, histological, and clinical evidence suggest that progestin's and progesterone receptors play an equally important growth of fibroids by modulating mitotic activity of uterine fibroids ${ }^{(38)}$. Hormonal factors are a potential link between diet and uterine fibroids because the risk may be increased by exposure to unopposed estrogen. Certain dietary components which could affect estrogen or progesterone may be implicated in the etiology of fibroids. A more likely explanation is that citrus fruit may reduce uterine fibroids risk through pathways mediated by sex steroid hormones, antioxidants, or both ${ }^{(39)}$.

This finding is congruent with that of Bani et al. (2013) ${ }^{(36)}$ who revealed that their mean score of fruits intake in healthy women was significantly more than women with myoma. Another study carried out by Wise et al. $(2011)^{(40)}$ had investigated the intake of fruit, vegetables, and carotenoids in relation to risk of uterine leiomyomata. They concluded that fruit intake was inversely associated with uterine leiomyomata risk, with the strongest reduction in risk observed for a high intake of citrus fruit

Generally speaking, the present study revealed no statistically significant difference between the study and control groups in relation to dairy foods intake (table 4). On the contrary, Wise et al. $(2010)^{(41)}$ who did a prospective study of dairy intake and risk of uterine leiomyomata. They found that both high-fat and low-fat dairy intakes were inversely associated with uterine leiomyomata risk among black women. They rationalize their findings by the fact that dairy foods have anti-tumorigenic components, including calcium, vitamin D. Calcium, a major component of dairy foods, may reduce fatinduced cell proliferation by maintaining intracellular calcium concentrations. Vitamin D may also play a protective role: It has been shown to decrease uterine leiomyoma cell proliferation in vitro, which 
give a protective effect of dairy consumption on uterine leiomyomata risk $^{(42)}$. A subsequent paper by the same authors noted that this relation could not be attributed to African ancestry ${ }^{(43)}$.

The present study revealed no statistically significant difference between the study and control groups in relation to sweet foods intake (table 4). This result contradicts the results of two other studies: where Kong S et al. (2014) ${ }^{(44)}$ who studied the association of hyperglycemia, hyperlipemia with the risk of uterine Leiomyomata and found that the high blood glucose might be a protective factor for uterine fibroid. They observed that women with the high blood glucose were less likely to develop uterine fibroid. Also Radin $\mathrm{R}$ et al. $(2010)^{(45)}$ studied the dietary glycemic index and load in relation to risk of uterine leiomyomata in the black women's health study. They concluded that the dietary glycemic index was associated with risk of uterine leiomyomata.

The result of the present study showed that, higher intake of fats is associated with increase development of uterine fibroids, where the intake of fats was statistically higher among the study group than the control one (table 4). This finding contradicts the finding of two studies: The First, Wise L et al. (2014) ${ }^{(46)}$ who studied the dietary fat and risk of uterine leiomyomata and concluded that there was little evidence that the consumption of total fat or fat subtypes overall were related to uterine leiomyomata risk. The Second, Nagata C et al. (2009) ${ }^{(47)}$ who investigated the association of intakes of fat, dietary fiber, soya isoflavones and alcohol with uterine fibroids in Japanese women. They found that there was no significant association of intakes of fats dietary fiber and soya isoflavones with the prevalence of fibroids.

The current study reported that physical activity was inversely associated with the development of uterine fibroids, where the physical activity level was statistically lower among the study group than the control one (table 5). This finding may be attributed to the fact that exercise can reduce circulating sex hormones and insulin levels ${ }^{(48)}$, thus limiting the proliferative effects that may be associated with these factors. The bioavailability of circulating estrogen might also be reduced by exercise-induced increases in sex hormone binding globulin. Exercise has also been hypothesized to influence estrogen metabolism such that fewer estrogenic metabolic products may be formed ${ }^{(49)}$. This finding is in accordance with $\mathrm{He}$ et al. $(2013)^{(33)}$ who found that the risk of fibroids significantly decreased among women who had moderate occupational intensity. In addition, Baird et al. (2006) ${ }^{(50)}$ reported that women were more likely to have decreased risk of fibroids when they had at least four hours of vigorous physical activity per week.

\section{Conclusion}

Based on the findings of this study, it can be concluded that higher intake of vegetables, grains and fruits and high physical activity are associated with a lower incidence of uterine fibroids. High intakes of meat and fats are associated with a higher development of uterine fibroids. In addition, the intake of fish, egg, dairy foods, sweets foods, cereals, breads, starches, beverages and salty foods have no association with uterine fibroids.

\section{Recommendations}

Based on the findings of the present study, the following recommendations are suggested:

- In-service training program to all nurses working in maternity and gynecological settings about the prevention of uterine fibroids through educating women about the importance of decreasing meat and fat intake as well as increasing intake of vegetables, grains and fruits. In 
addition, increased physical activity such as walking, household activities help in decreasing the occurrence of uterine fibroids.

- Relevant nursing curricula must entail a detailed portion about management and prevention of uterine fibroids by diet and physical activity.

- Future researches:

a. Replication of the present study under different circumstances (sampling, setting, measurement) is recommended to ensure the association of diet and physical activity with development of uterine fibroids.

b. Specialized studies are needed to explore the association of stress with development of uterine fibroids. 
Table (1): Distribution of study subjects according to their socio-demographic characteristics, age at marriage, smoking status and Body mass index

\begin{tabular}{|c|c|c|c|c|c|}
\hline \multirow{2}{*}{$\begin{array}{l}\text { Socio-demographic and Body } \\
\text { mass index }\end{array}$} & \multicolumn{2}{|c|}{$\begin{array}{c}\text { Study group }= \\
150\end{array}$} & \multicolumn{2}{|c|}{$\begin{array}{c}\text { Control group }= \\
150\end{array}$} & \multirow[t]{2}{*}{$\mathbf{x}^{2}(\mathbf{P})$} \\
\hline & No & $\%$ & No & $\%$ & \\
\hline $\begin{aligned} \text { Age (years): } & \\
- & 20- \\
- & 30- \\
- & 40-50\end{aligned}$ & $\begin{array}{l}35 \\
64 \\
51\end{array}$ & $\begin{array}{l}23.3 \\
42.7 \\
34.0\end{array}$ & $\begin{array}{l}42 \\
54 \\
54\end{array}$ & $\begin{array}{l}28.0 \\
36.0 \\
36.0\end{array}$ & $\begin{array}{c}1.57 \\
(0.456)\end{array}$ \\
\hline Mean \& SD & \multicolumn{2}{|c|}{$37.967 \pm 8.113$} & \multicolumn{2}{|c|}{$36.753 \pm 8.346$} & $1.277(0.2022)$ \\
\hline $\begin{array}{l}\text { Level of education: } \\
\begin{aligned} &- \text { Illiterate/read \& } \\
& \text { write } \\
&- \text { Primary/ preparatory. } \\
&- \text { Secondary } \\
&- \text { University } \\
&\end{aligned}\end{array}$ & $\begin{array}{c}5 \\
18 \\
75 \\
52\end{array}$ & $\begin{array}{l}03.3 \\
12.0 \\
50.0 \\
34.7\end{array}$ & $\begin{array}{c}2 \\
25 \\
69 \\
54\end{array}$ & $\begin{array}{l}01.3 \\
16.7 \\
46.0 \\
36.0\end{array}$ & $\begin{array}{c}2.713 \\
(0.438)\end{array}$ \\
\hline $\begin{aligned} & \text { Occupation: } \\
&- \text { Housewife } \\
&- \text { Working } \\
&\end{aligned}$ & $\begin{array}{l}90 \\
60\end{array}$ & $\begin{array}{l}60.0 \\
40.0\end{array}$ & $\begin{array}{l}93 \\
57\end{array}$ & $\begin{array}{l}62.0 \\
38.0\end{array}$ & $\begin{array}{c}0.126 \\
(0.723)\end{array}$ \\
\hline $\begin{aligned} & \text { Current residence: } \\
&- \text { Urban } \\
&- \text { Rural } \\
&\end{aligned}$ & $\begin{array}{l}78 \\
72 \\
\end{array}$ & $\begin{array}{l}52.0 \\
48.0\end{array}$ & $\begin{array}{l}69 \\
81\end{array}$ & $\begin{array}{l}46.0 \\
54.0\end{array}$ & $\begin{array}{c}1.08 \\
(0.299)\end{array}$ \\
\hline 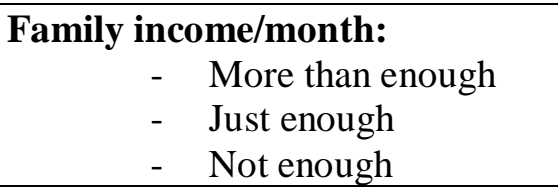 & $\begin{array}{l}18 \\
69 \\
63 \\
\end{array}$ & $\begin{array}{l}12.0 \\
46.0 \\
42.0\end{array}$ & $\begin{array}{l}12 \\
66 \\
72 \\
\end{array}$ & $\begin{array}{l}08.0 \\
44.0 \\
48.0\end{array}$ & $\begin{array}{l}1.867 \\
(0.393)\end{array}$ \\
\hline 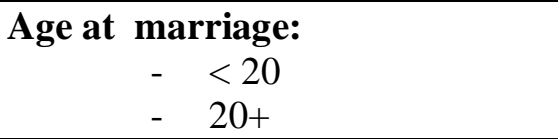 & $\begin{array}{l}60 \\
90\end{array}$ & $\begin{array}{l}40.0 \\
60.0\end{array}$ & $\begin{array}{l}69 \\
81\end{array}$ & $\begin{array}{l}46.0 \\
54.0\end{array}$ & $\begin{array}{c}1.102 \\
(0.294)\end{array}$ \\
\hline $\begin{array}{r}\text { Active smoking: } \\
-\quad \text { Yes } \\
-\quad \text { No } \\
\end{array}$ & $\begin{array}{c}0 \\
150\end{array}$ & $\begin{array}{c}00.0 \\
100.0\end{array}$ & $\begin{array}{c}0 \\
150\end{array}$ & $\begin{array}{c}00.0 \\
100.0\end{array}$ & -NA- \\
\hline 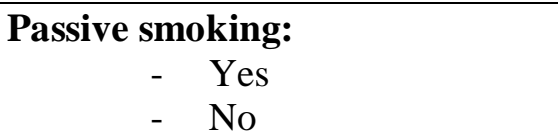 & $\begin{array}{l}84 \\
66\end{array}$ & $\begin{array}{l}56.0 \\
44.0\end{array}$ & $\begin{array}{l}72 \\
78\end{array}$ & $\begin{array}{l}48.0 \\
52.0\end{array}$ & $\begin{array}{l}1.923 \\
(0.166)\end{array}$ \\
\hline $\begin{array}{l}\text { Mean Body Mass Index (B M I): } \\
\text { Mean \& SD }\end{array}$ & 26. & 1.789 & 26.6 & 1.566 & $\begin{array}{c}0.893 \\
(0.373)\end{array}$ \\
\hline
\end{tabular}

$\chi^{2}(\mathrm{P}):$ Chi-Square Test $\& \mathrm{P}$ for $\chi^{2}$ Test

$\mathrm{T}(\mathrm{P})$ : T-test $\& \mathrm{P}$ for T-test

$*$ : Significant at $\mathrm{P} \leq 0.05$ 
Table (2): Distribution of the study subjects according to their menstrual history

\begin{tabular}{|c|c|c|c|c|c|}
\hline \multirow{2}{*}{ Menstrual history } & \multicolumn{2}{|c|}{ Study group $=150$} & \multicolumn{2}{|c|}{ Control group $=150$} & \multirow{2}{*}{$\mathbf{x}^{2}(\mathbf{P})$} \\
\hline & No & $\%$ & No & $\%$ & \\
\hline Mean age at menarche: & \multicolumn{2}{|c|}{$13.973 \pm 1.266$} & \multicolumn{2}{|c|}{$13.747 \pm 1.057$} & $1.685(0.093)$ \\
\hline $\begin{aligned} \text { Amount: } & \\
& - \text { Scanty } \\
& - \text { Moderate } \\
- & \text { Excessive }\end{aligned}$ & $\begin{array}{l}33 \\
78 \\
39\end{array}$ & $\begin{array}{l}22.0 \\
52.0 \\
26.0\end{array}$ & $\begin{array}{l}38 \\
70 \\
42 \\
\end{array}$ & $\begin{array}{l}25.3 \\
46.7 \\
28.0\end{array}$ & $\begin{array}{c}0.896 \\
(0.639)\end{array}$ \\
\hline $\begin{aligned} \text { Rhythm: } & \\
- & \text { Regular } \\
- & \text { Irregular }\end{aligned}$ & $\begin{array}{c}110 \\
40\end{array}$ & $\begin{array}{l}73.3 \\
26.7\end{array}$ & $\begin{array}{c}120 \\
30\end{array}$ & $\begin{array}{l}80.0 \\
20.0\end{array}$ & $\begin{array}{c}1.863 \\
(0.173)\end{array}$ \\
\hline $\begin{array}{l}\text { Mean duration: } \\
\text { Mean \& SD }\end{array}$ & \multicolumn{2}{|c|}{$5.973 \pm 0.794$} & \multicolumn{2}{|c|}{$6.033 \pm 0.746$} & $0.675(0.500)$ \\
\hline $\begin{array}{l}\text { Mean interval : } \\
\text { Mean \& SD }\end{array}$ & \multicolumn{2}{|c|}{$27.327 \pm 0.871$} & \multicolumn{2}{|c|}{$27.207 \pm 1.064$} & $1.069(0.286)$ \\
\hline
\end{tabular}

$\chi^{2}(\mathrm{P})$ : Chi-Square Test \& P for $\chi^{2}$ Test

$\mathrm{T}(\mathrm{P})$ : T-test $\& \mathrm{P}$ for T-test

*: Significant at $\mathrm{P} \leq 0.05$

Table (3): Distribution of the study subjects according to their reproductive history

\begin{tabular}{|c|c|c|c|c|c|}
\hline \multirow{2}{*}{ Reproductive history } & \multicolumn{2}{|c|}{ Study group $=150$} & \multicolumn{2}{|c|}{ Control group $=150$} & \multirow{2}{*}{$\begin{array}{c}\text { FET } / \mathbf{x}^{2} \\
\text { (P) }\end{array}$} \\
\hline & No & $\%$ & No & $\%$ & \\
\hline \multicolumn{6}{|l|}{ Gravidity: } \\
\hline - None & 3 & 02.0 & 0 & 00.0 & 3.648 \\
\hline$-\quad \leq 2$ & 60 & 40.0 & 68 & 45.3 & $(0.161)$ \\
\hline - 3 or more & 87 & 58.0 & 82 & 54.7 & \\
\hline Parity: & & & & & \\
\hline - None & 4 & 02.7 & 2 & 01.3 & 0.797 \\
\hline$-\quad \leq 2$ & 78 & 52.0 & 82 & 54.7 & $(0.671)$ \\
\hline - 3 or more & 68 & 45.3 & 66 & 44.0 & \\
\hline No. of abortion: & & & & & \\
\hline - None & 90 & 60.0 & 95 & 63.3 & 2.244 \\
\hline - One & 40 & 26.7 & 43 & 28.7 & $(0.326)$ \\
\hline$-\quad>$ One & 20 & 13.3 & 12 & 08.0 & \\
\hline
\end{tabular}

$\chi^{2}(\mathrm{P}):$ Chi-Square Test \& $\mathrm{P}$ for $\chi^{2}$ Test

FET (P): Fisher Exact Test \& P for FET-Test

$\mathrm{T}(\mathrm{P})$ : T-test \& $\mathrm{P}$ for T-test

*: Significant at $\mathrm{P} \leq 0.05$ 
Table (4): Distribution of the study subjects according to their consumption of food

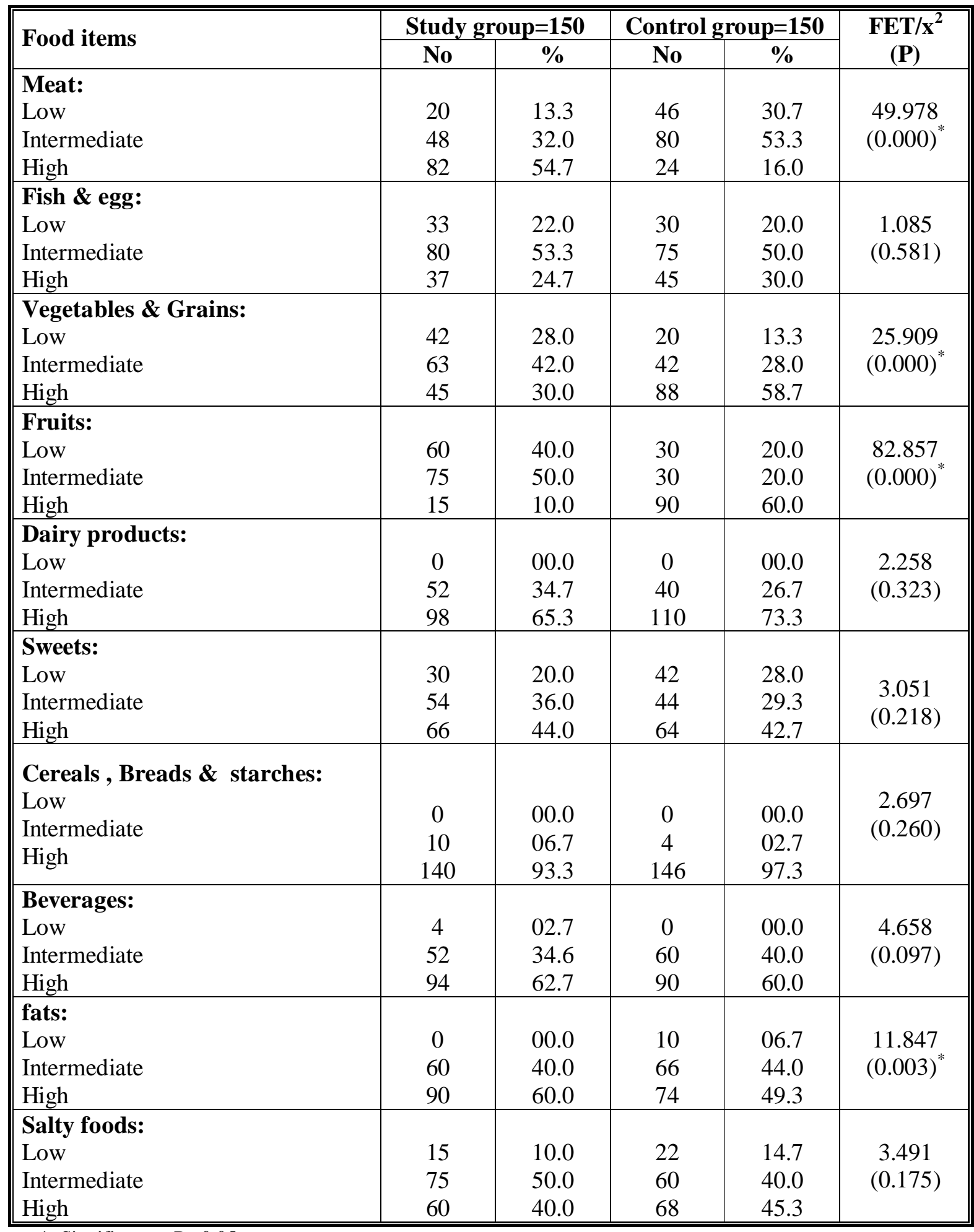

*: Significant at $\mathrm{P} \leq 0.05$

Low (never/less than one day per week)

Intermediate (one or two days per week)

High (three or more days per week). 
Table (5): Distribution of the study subjects according to their level of physical activity

\begin{tabular}{||l|c|c|c|c|c||}
\hline \multirow{2}{*}{ Physical activity level } & \multicolumn{2}{|c||}{ Study group=150 } & \multicolumn{2}{c||}{ Control group=150 } & \multirow{2}{*}{$\mathbf{x}^{2}(\mathbf{P})$} \\
\cline { 2 - 5 } & No & $\%$ & No & $\%$ & \\
Low active & 84 & 56.0 & 30 & 20.0 & \multirow{2}{*}{ \% } \\
Moderate active & 50 & 33.3 & 75 & 50.0 & \multirow{2}{*}{$(0.000)^{*}$} \\
High active & 16 & 10.7 & 45 & 30.0 & \\
\hline
\end{tabular}

$\chi^{2}(\mathrm{P})$ : Chi-Square Test $\& \mathrm{P}$ for $\chi^{2}$ Test $\quad$ *: Significant at $\mathrm{P} \leq 0.05$

Low active (achieved total physical activity less than 600 MET-minutes/weeks),

Moderate active (achieved total physical activity from 600 to less than 1500 MET-minutes/weeks)

High active (achieved total physical activity of 1500 or more MET-minutes/week). 


\section{References}

1. Okolo S. Incidence, etiology and epidemiology of uterine fibroids. Best Practice \& Research Clinical Obstetrics \& Gynaecology 2008; 22 (4): 571-588.

2. Catherino H, Eltoukhi M and Al-Hendy A. Racial and ethnic differences in the pathogenesis and clinical manifestations of uterine leiomyoma. Seminars in Reproductive Medicine 2013; 31(5): 370-379.

3. McLucas B. Diagnosis, imaging and anatomical classification of uterine fibroids. Clinical Obstetrics \& Gynecology 2008; 22(4): 627-642.

4. Fernandez H. Uterine fibroids. La Revue du praticien 2014; 64(4): 540-4.

5. Puri K, Famuyide O, Erwin J, Stewart A and Laughlin-Tommaso K. Sub mucosal fibroids and the relation to heavy menstrual bleeding and anemia. American Journal of Obstetrics \& Gynecology 2014; 210(1): 38.e1-7.

6. Abdullah L and Gomaa W. The Clinicopathological Characteristics of Uterine Leiomyomas: A Tertiary Care Centre Experience in Saudi Arabia. Report and Opinion 2013; 5(10):21-26.

7. Labergea P, Vilosb G, Vilosb A and Janiszewskic P. Burden of symptomatic uterine fibroids in Canadian women: a cohort study. Obstetrics and Gynecology 2016; 32(1): 165-175.

8. Vilos A, Allaire C, Laberge Y, Leyland $\mathrm{N}$, Murji $\mathrm{A}$ and Chen I. The management of uterine leiomyomas. Journal of Obstetricians and Gynecologists of Canada 2015; 37(2):157-178.

9. Cambridge I and Sealy P. Fibroids: a silent health problem affecting women in Trinidad and Tobago. Journal of the Department of Behavioral Sciences 2012; 2 (1):20-32.
10. Gavli M, Patel H, Anand N and Patel R. A Retrospective Study on Sociodemographic and Clinical Profile of Patients Underwent for Myomectomy. International Journal of Health Sciences \& Research 2015; 5(2):106-110.

11. Laughlin K, Schroeder C and Baird D. New Directions in the Epidemiology of Uterine Fibroids. Seminars in Reproductive Medicine 2010; 28 (3): 204-217.

12. Sarkodie B, Botwe B and Ofori E. Uterine fibroid characteristics and sonographic pattern among Ghanaian females undergoing pelvic ultrasound scan: a study at 3-major centers. BMC Women's Health 2016; 16(10): 1-6.

13. Jahanbin I, Aflaki E and Ghaem H .Relationship between Lifestyle Factors and Bone Density in Women Referring to Bone Densitometry Research Center in Shiraz, Iran. Women's Health Bulletin 2014; 1(1):12-16.

14. Opare-Addo H, Owiredu W, Dapilah T and Alhassan A. Putative Risk Factors among Ghanaian Women Presenting with Leiomyoma. British Journal of Medicine \& Medical Research 2014; 4(35): 5678-5688.

15. Kaaks R, Lukanova A and Kurzer M. Obesity, Endogenous Hormones, and Endometrial Cancer Risk: A Synthetic Review. Cancer Epidemiology, Biomarkers \& Prevention 2002; 11(1): 1531-1543.

16. The American Cancer Society Nutrition and Physical Activity Guidelines Advisory Committee. American Cancer Society Guidelines on Nutrition and Physical Activity for Cancer Prevention. CA: A Cancer Journal for Clinicians 2012; 62(1): 30-67.

17. Moore SC, Gierach GL, Schatzkin A et al. Physical activity, sedentary 
behaviours, and the prevention of endometrial cancer. British Journal of Cancer 2010; 103: 933-8.

18. Friedenreich CM, Neilson HK, Woolcott CG et al. Mediators and moderators of the effects of a year-long exercise intervention on endogenous sex hormones in postmenopausal women. Cancer Causes Control 2011; 22: 136573.

19. Block G, Hartman M and Naughton D. A reduced dietary questionnaire: development and validation. Epidemiology 1990; 1(1): 58-64.

20. IPAQ Research Committee. Guidelines for data processing and analysis of the International Physical Activity Questionnaire (IPAQ). Short form. Stockholm: Karolinska Institute, 1998. http://www.ipaq.ki.se/scoring.pdf. (Accessed 5 July 2014).

21. Ainsworth E, Haskell L, Leon D, Jacobs $\mathrm{R}$, Montoye J, Sallis F and Paffenbarger S. Compendium of physical activities: classifications of energy costs of human physical activities. Medicine and Science in Sports and Exercise 1993; 25(1): 71-80.

22. El-Gilany A, Badawi K, El-Khawaga G and Awadalla N. Physical activity profile of students in Mansoura University, Egypt. Eastern Mediterranean Health Journal 2011; 17 (8): 694-702.

23. Nucci $R$ and Quade J. Diagnostic Gynecologic And obstetric Pathology. $2^{\text {nd }}$ ed. Saunders: an imprint of Elsevier Inc; 2011, 612.

24. Reding1 K, Atkinson C, Westerlind K, Stanczyk F, Bowles E, Yong M, Katherine M. Newton K and Lampe J. Fruit intake associated with urinary estrogen metabolites in healthy premenopausal women. Open Journal of Preventive Medicine 2012; 2(1):1-8.
25. Wise L, Palmer J, Harlow B, Spiegelman D, Stewart E, AdamsCampbell L. Reproductive factors, hormonal contraception and risk of uterine leiomyomata in African-American women: a prospective study. American journal of epidemiology 2004; 159(2): 113-123.

26. Wise L, Palmer J, Spiegelman D, Harlow B, Stewart E, Adams-Campbell L, Rosenberg L. Influence of body size and body fat distribution on risk of uterine leiomyomata in U.S. black women. Epidemiology 2005; 16(1):34654.

27. Terry K, De Vivo I, Hankinson S, Missmer S. Reproductive characteristics and risk of uterine leiomyomata. Fertility and Sterility. 2010; 94(7): 2703-2707.

28. KhanT, Shehmar M and Gupta K. Uterine fibroids: current perspectives. International Journal of Women's Health 2014; 6: 95-114.

29. Stewart E and Solomon C. Uterine Fibroids. The New England Journal of Medicine 2015; 372(17): 1646-1655.

30. Flake G, Andersen J and Darlene D. Etiology pathogenesis of uterine leiomyomas: a review. Environmental health perspectives 2003; 111(8): 10371041.

31. Chiaffarino F, Parazzini F, La Vecchia C, Chatenoud L, Di Cintio E and Marsico S. Diet and Uterine Myomas. Obstetrics \& Gynecology 1999; 94(3):395-398.

32. Parazzini F, Chiaffarino F, Surace M, Chatenoud L, Cipriani S, Chiantera V, Benzi G and Fedele L. Selected food intake and risk of endometriosis. Human Reproduction 2004; 19(8): 1755-1759. 
33. He Y, Zeng Q, Dong S, Qin L, Li G and Wang P. Associations between uterine fibroids and lifestyles including diet, physical activity and stress: a casecontrol study in China. Asia Pacific Journal of Clinical Nutrition 2013; 22(1): 109-117.

34. Aubertin-Leheudre M, Hamalainen E and Adlercreutz H. Diets and hormonal levels in postmenopausal women with or without breast cancer. Nutrition and Cancer 2011; 63:514-24.

35. Pizzorno E and Murray T. Textbook of natural medicine. $4^{\text {th }}$ ed. St. Louis, MO: Elsevier Churchill Livingstone; 2013.

36. Bani S, Hasanpour S, chaychi S, Ebrahimi $\mathrm{H}$ and Mamaghani $\mathrm{M}$. Leiomyoma and Nutrition, a CaseControl Study. International Journal of Women's Health and Reproduction Sciences 2013; 1(1): 5-13.

37. Sahin K, Ozercan R, Onderci M, Sahin N, Khachik F, Seren S and Kucuk O. Dietary tomato powder supplementation in the prevention of leiomyoma of the oviduct in the Japanese quail. Nutrition and Cancer 2007; 59(1):70-75.

38. Atkinson C, Lampe J, Scholes D, Chen C, Wa"ha"la $\mathrm{K}$ and Schwartz S. Lignan and isoflavone excretion in relation to uterine fibroids: a case-control study of young to middle-aged women in the United States. The American Journal of Clinical Nutrition 2006; 84 (3):587593.

39. Zhang C, Suzanne C, Chen Y, Fu J, Cheng $\mathrm{S}$ and Lin F. Greater vegetable and fruit intake is associated with a lower risk of breast cancer among Chinese women. International Journal of Cancer 2009; 125(1):181-188.

40. Wise L, Radin R, Palmer J, Kumanyika S, Boggs D and Rosenberg L. Intake of fruit, vegetables, and carotenoids in relation to risk of uterine leiomyomata.
The American Journal of Clinical Nutrition 2011; 94 (1):1620-31.

41. Wise L, Radin R, Palmer J, Kumanyika $\mathrm{S}$ and Rosenberg L. A Prospective study of dairy intake and risk of uterine Leiomyomata. American Journal of Epidemiology 2010; 171(2): 221-232

42. Sharan C, Halder K and Thota C. Vitamin $\mathrm{D}$ inhibits proliferation of human uterine leiomyoma cells via catechol-O-methyltransferase. Fertility and Sterility 2011; 95(1): 247-253.

43. Wise A, Palmer R, Ruiz-Navarez E, Reich E and Rosenberg L. Is the observed association between dairy intake and fibroids in African Americans explained by genetic ancestry? The American Journal of Epidemiology 2013; 178(7): 1114-1119.

44. Kong S, Hou J, Xia M, Yang Y, Xu A and Tang Q. Association of Hyperglycemia, Hyperlipemia with the Risk of Uterine Leiomyomata: A CaseControl Study. Cancer Cell Research 2014; 2 (1): 37-41.

45. Radin R, Palmer J, Rosenberg L, Kumanyika $\mathrm{S}$ and Wise L. Dietary glycemic index and load in relation to risk of uterine leiomyomata in the Black Women's Health Study. The American Journal of Clinical Nutrition 2010; 91(1):1281-8.

46. Wise L, Radin R, Kumanyika S, RuizNarva E, Palmer $\mathbf{J}$ and Rosenberg L. Prospective study of dietary fat and risk of uterine leiomyomata. The American Journal of Clinical Nutrition 2014; 99(5):1105-16.

47. Nagata C, Nakamura N, Oba S, Hayashi $\mathrm{M}$, Takeda $\mathrm{N}$ and Yasuda $\mathrm{K}$. Association of intakes of fat, dietary fibre, soya isoflavones and alcohol with uterine fibroids in Japanese women. British Journal of Nutrition 2009; 101(10): 1427-1431. 
48. McTiernan A, Tworoger S and Ulrich M. Effect of exercise on serum estrogens in postmenopausal women: a 12-month randomized clinical trial. Cancer Research 2004; 64 (8): 2923-8.

49. Smith A, Phipps W, Thomas W, Schmitz K and Kurzer M. The Effects of Aerobic Exercise on Estrogen Metabolism in Healthy Premenopausal Women. Cancer Epidemiology,
Biomarkers \& Prevention 2013; 22(5): 756-764.

50. Baird D, Dunson D, Hill M, Cousins D and Schectman J. Association of Physical Activity with Development of Uterine Leiomyoma. American Journal of Epidemiology 2007; 165(2):157-163. 